\title{
O ESVAZIAMENTO DA DIDÁTICA E DA PEDAGOGIA NA (NOVA) BNC DE FORMAÇÃO INICIAL DE PROFESSOR DA EDUCAÇÃO BÁSICA
}

\author{
Aline D. N. MASCARENHAS ${ }^{\mathrm{i}}$ \\ Maria Amélia Santoro FRANCO ${ }^{\text {ii }}$
}

\begin{abstract}
RESUMO
Este estudo, de natureza ensaística, analisa a recente Resolução CNE 02/2019, que estabelece a Base Nacional Comum para a Formação Inicial de Professores da Educação Básica. O texto pretende desvelar as intencionalidades político-ideológicas contidas no referido documento. Para tanto, toma como questão de pesquisa: Quais intencionalidades político-ideológicas se corporificam nas referidas diretrizes? Os resultados indicam que o ideário proposto se pauta numa compreensão meramente tecnicista da docência, ancorado na pedagogia neoliberal que se reverbera no campo da profissionalização docente, induzindo a práticas reducionistas de formação, reconduzindo-as a uma concepção instrumental e acrítica da didática e ao retrocesso epistemológico da pedagogia das competências de cunho behaviorista.
\end{abstract}

PALAVRAS-CHAVE: Didática; Formação de professor; Resolução CNE 02/2019.

\section{THE EMPTYING OF DIDACTS AND PEDAGOGY IN THE (NEW) BNC INITIAL EDUCATION OF BASIC EDUCATION TEACHER}

\begin{abstract}
This essay, written how essayistic nature, analyzes the recent CNE Resolution 02/2019 that establishes the Common National Base for the Initial Formation of Teachers of Basic Education. The text intends to unveil the political-ideological intentions contained in that document. Therefore, it takes as research question: What political-ideological intentions are embodied in the referred guidelines? The results indicate that the proposed idea is based on a technicist understanding of teaching, anchored in the neoliberal pedagogy that reverberates in the field of teacher professionalization, leading to reductionist training practices, bringing them back to an instrumental and uncritical conception of didactics and to the epistemological regression of the pedagogy of behaviorist skills.
\end{abstract}

KEYWORDS: Didactics; Teacher education; CNE Resolution 02/2019.

\footnotetext{
${ }^{i}$ Doutora em Educação pela UFBA. Professora adjunta da UNEB. E-mail: aline mascarenhas@hotmail.com ORCID iD: https://orcid.org/0000-0003-0382-4120.

ii Doutora em Educação. Pós-doutorado em Pedagogia. Professora titular Universidade Católica de Santos. Pesquisadora CNPq. E-mail: amelia@ unisantos.br - ORCID iD: http://orcid.org/0000-0003-3867-5452.
} 


\title{
EL VACÍO DE LA ENSEÑANZA Y LA PEDAGOGÍA EN LA (NUEVA) EDUCACIÓN INICIAL DEL MAESTRO DE EDUCACIÓN BÁSICA DEL BNC
}

\begin{abstract}
RESUMEN
Este ensayo, de carácter ensayístico, analiza la reciente Resolución CNE 02/2019 que establece la Base Común Nacional para la Formación Inicial de Docentes de Educación Básica. El texto pretende desvelar las intenciones político-ideológicas contenidas en ese documento. Por tanto, se toma como pregunta de investigación: ¿Qué intenciones político-ideológicas se plasman en los referidos lineamientos? Los resultados indican que la idea propuesta se sustenta en una comprensión tecnicista de la enseñanza, anclada en la pedagogía neoliberal que repercute en el campo de la profesionalización docente, conduciendo a prácticas formativas reduccionistas, devolviéndolas a una concepción instrumental y acrítica de la didáctica y a la regresión epistemológica de la pedagogía de las habilidades conductistas.
\end{abstract}

PALABRAS CLAVE: Didáctica; Formación de profesores; Resolución CNE 02/2019.

\section{INTRODUÇÃO}

As disputas nos projetos de formação de professores no atual cenário brasileiro têm causado grande preocupação aos pesquisadores implicados com essa discussão; o atual contexto é dramático e nos convida a um movimento de insurgência e re(existência) diante da concepção de uma educação e de um modelo formativo docente calcado numa lógica meramente tecnicista, aplicacionista, ancorado na pedagogia neoliberal com ênfase nas competências e na lógica reguladora de avaliação, reconfigurando o campo da profissionalização e profissionalidade do professor, conduzindo a formação ao reducionismo do conhecimento pedagógico e a uma concepção demasiadamente pragmatista.

A atual discussão parece nos levar "de volta ao passado", precisamente na década de 90, quando o campo da educação e da formação de professores caminhava ao encontro do tecnicismo e aplicacionismo pedagógico em um tom de discurso ancorado na "qualidade total da educação" (GENTILI, 1994; FRIGOTTO, 1994). Contudo, as recentes orientações do Parecer que institui a Resolução CNE 02/2019, que estabelece a Base Nacional Comum para a Formação Inicial de Professores da Educação Básica (BNCFP), evidenciam que a década de 90 está por vir, revestida de um discurso estreito com a pedagogia das competências, tendo como travessia a Base Nacional Comum Curricular da educação básica.

É fato que a Resolução CNE 02/2015, que instituiu as Diretrizes Curriculares Nacionais para a formação inicial em nível superior e para a formação continuada, que ainda 
estava em vigor (até dezembro de 2019) no ordenamento dos cursos de formação de professores no país, trazia questões mal resolvidas no campo da formação de professores, mas havia a esperança (ainda que ingênua) de que as novas diretrizes que estavam para ser lançadas, no terreno das políticas de formação de professores, pudessem avançar em pautas importantes no que concerne a uma nova especificidade da identidade profissional do professor; à defesa na profissionalização docente, à recusa quanto à possibilidade de complementação pedagógica para graduados de outras áreas galgarem um diploma na licenciatura, e à ênfase, ainda presente, nos conhecimentos das disciplinas específicas com resquícios da compartimentação teórica e prática. Tais questões se apresentavam como um terreno frágil e, portanto, questionável na Resolução 02/2015 de formação de professores, que, mesmo desenhada em conjunto com entidades, movimentos e universidades - sendo, portanto, um documento legítimo e democrático que acatava as pesquisas realizadas por universidades e professores pesquisadores da área - não era um documento de total consenso quanto à proposta, mas se concretizava numa importante conquista com pautas progressistas.

A atual Diretriz Curricular Nacional para a Formação Inicial em Nível Superior de Professores para a Educação Básica, que institui a Base Nacional Comum para a Formação Inicial de Professores da Educação Básica (DCN-BNC), amplia os problemas anteriores, ferindo princípios básicos da formação de professores, excluindo do debate importantes entidades que há décadas defendem um projeto de formação docente no país, a exemplo da Associação Nacional de Formação de Professores (Anfope) e da Associação Nacional de Pósgraduação em Pesquisa e Educação (Anped).

Além disso, a Diretriz invisibilizou e rechaçou o trabalho das universidades, abrindo o canal de diálogo apenas para os agentes ligados ao "Movimento Todos pela Educação"1, que na sua essência são "reformadores empresarias da educação" (FREITAS, 2018). Como exemplo, a Fundação Lemann e Itaú social, que têm interferido e gerenciado as políticas educacionais com uma forte influência na aprovação da Resolução CNE/CP n ${ }^{\circ}$, de 22 de dezembro de 2017, que institui e orienta a implantação da Base Nacional Comum na Educação Básica, e a Resolução CNE 02/2019. Esta, por sua vez, define as Diretrizes Curriculares Nacionais para a Formação Inicial de Professores para a Educação Básica e institui a Base Nacional Comum para a Formação Inicial de Professores da Educação Básica (BNC-Formação de professor). 
Esse movimento dos reformadores empresariais da educação utiliza o discurso de neutralidade partidária, camufla suas narrativas em pautas historicamente ligadas aos movimentos sociais em defesa da educação, a exemplo do direito à educação, educação integral, acesso democrático e permanência escolar, sendo compreendido como uma "nova filantropia" (BALL; OLMEDO, 2013)², que tem direcionado a agenda educacional no país.

Nesse cenário, os cursos de licenciatura alteram os princípios formativos da profissionalização do professor e a sua profissionalidade, num campo de disputas que culmina com a "finalização perfeita" de um projeto de desmonte da educação, ao ancorar a formação docente inicial a um caráter técnico, relegando a Didática e a Pedagogia a uma propensão meramente instrumental, produzindo apenas fazeres de reprodução ao invés da construção crítica e emancipatória dos saberes docentes, abrindo, assim, espaço a uma lógica empresarial. Desse modo, distancia-se a formação inicial de professores de uma visão crítica, de um compromisso com a práxis educativa, afastada de um terreno profissional no âmbito político, histórico, ético, social e intercultural.

Assim, vêm se construindo traços de uma profissionalidade distanciada do campo da Didática Geral, aproximando a formação docente ao campo do treinamento, a aprendizagem numa perspectiva motivacional, com ênfase no behaviorismo, como se o processo de aprendizagem fosse exógeno e o ensino uma atividade praticista, fundamentada em "manejo de ritmos em um processo motivacional" (BRASIL, 2019, p. 6).

No horizonte ordenado por essas questões introdutórias, este estudo pretende desvelar os pressupostos no campo epistemológico da Didática, os elementos formativos, políticos e ideológicos presentes na Resolução CNE 02/2019, que orientam as diretrizes de formação inicial de professores da educação básica e, assim, investigar: Quais intencionalidades políticas se corporificam nas Diretrizes para a Formação Inicial de Professores da Educação Básica (Resolução 02/2019)? Quais intencionalidades estão ocultadas nesse documento oficial? Quais as implicações de atrelar o processo de formação de professor a competências de uma BNCC da educação básica? Qual a concepção de Didática presente nesse documento oficial? 
Este ensaio teórico se consubstancia em estudos documentais de documentos oficiais no campo da formação docente, estudos teóricos, além de pesquisas de escuta e observação ${ }^{3}$ com docentes da rede pública de ensino, no espaço do grupo de pesquisa dos autores ${ }^{4}$.

As discussões aqui tecidas têm o caráter crítico para a construção de movimentos de enfrentamentos à colonização neoliberal do campo da formação de professores, instigando a problemática da profissionalização docente como política de formação e como arena de resistência para fortalecimento da escola pública, gratuita e laica.

\section{BREVE HISTÓRICO DA RESOLUÇÃO CNE 02/2019}

É fato que a formação de professores é algo que precisa ser retomado e discutido sempre, face às problemáticas que ainda persistem no contexto de profissionalização docente e diante de um cenário que visivelmente se encontra fragilizado. Embora não se pretenda aqui analisar todas as políticas no campo de formação de professores ao longo das décadas no cenário brasileiro, cabe situar ao menos o documento legal vigente até o final do ano de 2019, a Resolução CNE 02/2015, que instituiu as Diretrizes Curriculares Nacionais para a formação inicial em nível superior e para a formação continuada, orientando os currículos das licenciaturas no Brasil.

A Resolução de 02/2015 trazia, por um lado, alguns pontos emergentes e que careciam de mais discussão, diante da complexidade e do reconhecimento de uma sociedade plurifacetada que precisa ser visibilizada nos currículos de formação do professor, a partir da inclusão de temáticas importantes, como: direitos humanos, orientação sexual, educação étnico-racial, educação indígena, educação quilombola, educação inclusiva e educação do sistema prisional; por outo lado, defendia uma bandeira equivocada e sem precedentes no processo de aligeiramento da formação do professor, precarizando o terreno da profissionalização docente a partir da defesa da formação pedagógica para graduados não licenciados. A nosso olhar, esse aspecto é uma fissura incompreensível que retrocede a formação e se aproxima novamente do "esquema 3+1", que dicotomizava o bacharelado e as licenciaturas numa nova roupagem, descrita como "Cursos de formação pedagógica para graduados não licenciados” (BRASIL, 2015) e, ainda, presente na Resolução 02/2019 como “Da formação Pedagógica para Graduandos" (BRASIL, 2019, p. 10). 
No Brasil, desde 2016, com o golpe que afastou a Presidenta Dilma Rousseff, vivenciamos um desmonte na educação e no campo de formação de professores a partir de ideias ultraconservadoras nas políticas educacionais, alterando a proposta emancipatória e inclusiva do governo, que vinha sendo gerenciada pelos mandatos de Lula e Dilma Rousseff. Assim, fomos vivenciando um processo de obscurecimento, autoritarismo, falta de diálogo, negação da ciência, conservadorismo e um recorrente discurso de descrédito das universidades.

Nesse horizonte, se instalam resquícios no âmbito das políticas de formação de professores e vai se tramando a institucionalização de uma nova diretriz de professor, mais adequada às ideias conservadoras. Nesse cenário, em 20 de dezembro de 2019 é aprovada a Resolução CNE 02/2019, que altera a Resolução 02/2015, instituindo as Diretrizes Curriculares Nacionais para a Formação Inicial em Nível Superior de Professores para a Educação Básica e institui a Base Nacional Comum para a Formação Inicial de Professores da Educação Básica (DCN-BNC). A Resolução CNE 02/2019 está baseada numa lógica de princípios formativos dissonantes da Resolução 02/2015, que ainda estava em vigor e nem ao menos havia sido avaliada. Aliás, as instituições de ensino superior que formam professores estavam num processo de readequação curricular dos cursos de Licenciaturas com base na Resolução 02/2015, redefinindo seus projetos com foco numa concepção mais humanista, crítica, estética, política e vinculada à prática pedagógica implicada com a práxis.

Assim, a Resolução CNE 02/2015 foi suprimida pela Resolução CNE 02/2019, inicialmente ancorada no discurso da complementariedade, mas logo após a aprovação foi despida desse teor, ao evidenciar um projeto de favorecimento da lógica das competências, atrelando a formação do professor à exequibilidade da Base Nacional Comum Curricular da Educação Básica (BNCC), referendada nas Resoluções CNE-CP nº 02/2017 e CNE-CP n ${ }^{\circ}$ 04/2018, eclipsando os fundamentos epistemológicos da Pedagogia e a da Didática em favor de uma "lógica neotecnicista" (FREITAS, 2018) e neoliberal.

Desse modo, processo formativo inicial nos cursos de licenciatura mediante a nova orientação invisibiliza a educação enquanto dimensão histórico-crítica e social, invertendo a lógica formativa do professor para atender às competências estabelecidas pela BNCC da 
educação básica e não mais pautada no compromisso com o projeto social, político e ético, conforme preconizava a Resolução 02/2015.

Importa ressaltar que o Parecer de atualização da Resolução CNE/CP nº 02/2019, que instituiu e definiu a implementação da Base Nacional Comum de formação inicial de professores da educação básica, faz um estudo utilizando um campo teórico de contextos internacionais, a exemplo de países como Austrália, Alemanha e EUA, rechaçando pesquisadores brasileiros que há décadas produzem pesquisas no âmbito da formação docente. Ao longo do documento, fica evidente o seu caráter deslocado do aspecto histórico e social, sem levar em conta as desigualdades escolares, presentes entre as classes sociais do país, números elevados de repetência e evasão escolar, a recente obrigatoriedade de formação de professores em nível superior, problemas avassaladores da escola pública diante da falta de investimento na educação pública.

A realidade na qual se fundamenta o atual parecer que dá origem a essa Base Nacional Comum de Formação de Professor da educação básica é totalmente descontextualizada da realidade brasileira e utiliza de maneira fantasiosa, em seu estudo comparativo, países de primeiro mundo, cuja desigualdades sociais não são gritantes como no Brasil, partindo de um pressuposto equivocado e "cínico" para adotar uma política de formação docente calcada nas competências de Perrenoud (1999) e marcos regulatórios de avaliação no campo docente com ênfase em "premiações".

\section{PRESSUPOSTOS FORMATIVOS E PEDAGÓGICOS NA ATUAL POLÍTICA}

Nosso entendimento é o de que os movimentos institucionais, decorrentes de políticas públicas propostas e implantadas de modo não participativo, trazem de forma sub-reptícia, travestida de um discurso supostamente contemporâneo, a intenção de desautonomização e desautorização dos professores, de forma a torná-los pouco críticos, reprodutores de orientações que surgem de fora das escolas, impedindo-lhes de tomar decisões por si e pelo coletivo de docentes.

Nesse sentido, Shiroma e Evangelista (2004, p. 535) já afirmavam há mais de uma década: 
[...] a política de profissionalização de professores e gestores, nos moldes em que vem sendo implantada, tem por objetivo não o aumento da qualificação do quadro de magistério, mas sim, a sua desintelectualização para, desse modo, torná-los pragmáticos, diminuindo-lhes a capacidade de intervenção consciente.

Esse processo de retirar dos docentes o protagonismo intelectual vem se estruturando de forma contínua e global. Temos visto, nas últimas décadas, o aumento do controle do Estado sobre a prática docente, por meio de uma formação inicial precária e sem os fundamentos da ciência pedagógica e da didática, transformando-a num treinamento de fazeres, cada vez mais esvaziada e empobrecida.

Temos acompanhado o progressivo processo de proletarização e pauperização do trabalho docente, o que tem gerado uma gradativa perda de controle do próprio docente sobre os processos que estruturam seu trabalho e, além disso, produzindo o desconhecimento da própria tarefa que lhe é incumbida. A formação transformou-se numa semiformação, na perspectiva de Adorno, gerando, entre outras coisas, a despersonalização do papel social do docente.

Pode o professor continuar sendo professor assim tão desautorizado? Pode o professor construir processos críticos de profissionalização, sem a necessária autonomia política e intelectual?

Apesar de muitos estudos e pesquisas alertarem para a necessária inclusão do pensamento do professor nas tendências investigativas na área da docência, há décadas vem sendo gestada a exclusão do docente na produção de conhecimento referente às suas condições de trabalho. Lisita (2005) cita o estudo de Torres (1998) sobre as tendências da formação docente nos anos 1990 que revelam que as diretrizes do Banco Mundial (principal instância indutora de políticas para a América Latina) para as reformas educacionais na região basearam-se em pesquisas realizadas em 18 países "em desenvolvimento", dois quais apenas dois eram da América Latina. Entre essas diretrizes para a formação de professores, no contexto das reformas, destacam-se as seguintes: a ênfase na formação docente em serviço; a prioridade para a formação à distância dos professores e para a utilização do livro didático em substituição ao trabalho do professor. Realça o autor, ainda, a ênfase na capacitação docente como uma dimensão isolada, independente de outros fatores igualmente importantes para melhorar o sistema educacional. A implementação das reformas, desde os anos 1980, segue 
um esquema básico: 1) uma equipe de técnicos define as linhas gerais da reforma e o desenho do documento; 2) informa-se a população das mudanças que serão implementadas; 3) capacitam-se os professores para a execução da reforma.

Como se verifica, os professores são vistos apenas como executores passivos das reformas; para essa tarefa de coisificação do docente ser bem sucedida, será preciso que os professores recebam uma formação castradora, bancária e sem autonomia intelectual, de forma que aprendam a não pensar, a não criar, a não investigar e que apenas executem decisões postas à sua frente.

\section{A DeSProfissionalizaÇão eM CURSO: A PRÁtica Pedagógica DOCENTE IMOBILIZADA}

Kincheloe (1997) vem sistematicamente criticando o acelerado controle do Estado sobre as atividades de ensino, que afeta não só o trabalho docente, mas a concepção do papel social docente, provocando tanto a perda da sua autonomia profissional quanto o desgaste de sua imagem social. Sem autonomia, os docentes ficam encurralados em processos de domesticação intelectual, o que vai produzindo o distanciamento continuado entre o pensar e o fazer; entre o educativo e o pedagógico.

Assim, vai se criando uma cultura de passividade intelectual, incompatível com o que se espera da formação docente em termos de criatividade, flexibilidade, autonomia. Nesse sentido, o Parecer de atualização da Resolução CNE/CP nº 02/2019 reforça essa dissonância no momento que atrela a formação do professor à garantia das competências da BNCC (educação básica), invertendo a lógica do processo formativo e eclipsando a educação como dimensão sócio-histórica, estabelecendo, assim, uma reconversão colonial no campo da formação inicial do professor.

A BNC da formação inicial do professor tem o objetivo explícito de gerenciar a formação e a prática pedagógica docente via processo de padronização curricular, destituindo o terreno curricular das Licenciaturas do ato político e cultural, reduzindo o papel do professor em sua esfera crítica, criativa, autônoma, política e intercultural. Outra questão decorrente é a excessiva padronização exigida dos processos de formação docente, na intencionalidade de facilitar o controle das práticas, produzindo, assim, uma percepção de 
que as práticas pedagógicas podem ser controladas, engessadas, previsíveis e que cabe ao professor apenas ser mais um controlador de resultados.

Essa situação retira o sentido das práticas e gera nos alunos e professores a sensação de aridez e desnecessidade de liberar processos de curiosidade epistemológica. Grande erro das políticas públicas é tentar transformar processos intelectuais que fundamentam a prática pedagógica em procedimentos técnicos de transmitir conteúdos. Em que natureza se ancoram os princípios da prática educativa na atual Diretriz de formação de professor?

A concepção de prática presente na atual Diretriz está cravejada em um aplicacionismo estéril ${ }^{5}$, descolado dos saberes docentes, no vazio epistemológico da Pedagogia Crítica e da Didática, promovendo uma dimensão de prática pedagógica empobrecida em um saber-fazer, alinhada à execução da garantia de conteúdos e competências, interferindo também na cultura e autonomia escolar. Assim, corroboramos a análise de D’Ávila (2020, p. 9):

[...] a dimensão Prática profissional e seu elenco de competências acentua, mais uma vez: o cognitivsmo (ensino baseado quase que exclusivamente nos processos mentais dos alunos); no tecnicismo (no domínio de técnicas e recursos tecnológicos voltados às experiências de aprendizagem) e no praticismo (formação do professor prático), como dimensão aparentemente inócua de sentido político-social.

A práxis pedagógica é complexa e exige processos de interformação, de modo a se considerar a unidade teoria prática numa dimensão crítica e multidimensional. Como escreve Vásquez (1977, p. 117):

Com Marx, o problema da práxis, como atitude humana transformadora da natureza e da sociedade, passa para o primeiro plano. A filosofia se torna consciência, fundamento teórico e seu instrumento. A relação entre teoria e práxis é para Marx teórica e prática; prática, na medida em que a teoria, como guia da ação, molda a atividade do homem, particularmente a atividade revolucionária; teórica, na medida em que essa relação é consciente.

Ou seja, a formação docente não pode regredir a pensar que processos formativos se façam à revelia de movimentos articuladores da teoria na prática e na prática, que é teoria. $\mathrm{O}$ parecer parece desconhecer esse imperativo formativo e pretende retornar à pedagogia das competências, que ignora a dinâmica formativa. 
Hargreaves (1999) considera que a autoridade social e autonomia intelectual são categorias fundamentais para conduzir o processo de desenvolvimento profissional docente. No entanto, alerta que esse desenvolvimento requer a adesão da sociedade e deve se expressar nas políticas públicas de educação, de modo a reforçar a responsabilidade social do professor com a formação de crianças e jovens. Esse compromisso social vai deixando de existir se a sociedade e as instituições de ensino solicitarem o professor apenas como transmissor de conteúdos que sequer foram reinterpretados por ele. Apple (1982, p.22), já afirmava que quando as pessoas deixam de planificar e de controlar o próprio trabalho, "as destrezas essenciais para cumprir estas tarefas de forma reflexiva e bem conseguida, atrofiam-se e são esquecidas". E dizemos mais, muitas vezes nem são adquiridas!

Reforçamos esse ponto de vista, ainda, com Kincheloe (1997, p. 28), ao afirmar: "eles parecem não se dar conta de que o ensino é inerentemente um ato de incerteza e que qualquer tentativa para negar esta característica acaba em problema". Os problemas estão aí abertos a nossos olhos e os pareceres demonstram ignorar tais evidências. Assim, a prática educativa, de tanto se padronizar, vai sendo tratada e percebida numa perspectiva mecanicista, destituindo os professores de poder e de autoridade moral para atuarem como intelectuais da/na prática.

Os professores não podem ser considerados apenas reprodutores de mudanças propostas por técnicos que, muitas vezes, desconhecem as necessidades pedagógicas de alunos; será preciso resgatar o propósito intelectual/moral que deve subsidiar a tarefa pedagógica. Sabe-se que professores formados na perspectiva tecnicista e incentivados institucionalmente a serem, nas escolas, reprodutores de orientações técnicas acabam perdendo a capacidade de questionamento, de investigação da própria prática e assumindo posturas de inflexibilidade intelectual. Nesta perspectiva, de tamanha despersonalização docente, os espaços para desenvolvimento profissional parecem ser desnecessários.

\section{A RESOLUÇÃO CNE 02/2019: O QUE QUER? QUE PRINCÍPIOS PEDAGógICOS?}

A Resolução 02/2019 tem a pretensão de orientar a formação inicial de professores e reorganizar os currículos das licenciaturas. No entanto, tal parecer funda-se numa concepção 
de um modelo formativo pautado em uma prática tecnicista, instrumental, destituída do caráter reflexivo, com estreita relação com a BNCC (conteudista), alinhada com a lógica de uma prática vinculada apenas a um saber-fazer e distante da relação com o processo de educação e humanização. É uma diretriz que instiga uma prática docente esvaziada, distante do sentido de uma práxis.

Essa dimensão esvaziada presente no contexto brasileiro trafega na linha de uma "política itinerante" (OLIVEIRA, 2020; POPKEWITZ, 2008) de formação dos professores na América Latina, através de recentes acordos internacionais com base no discurso da qualidade mensurada de maneira censitária, instituindo a figura do professor em um "neosujeito" (DARDOT; LAVAL, 2016), que se configura como uma "empresa" que está em contínua concorrência, ou seja, a transformação dos indivíduos em sujeitos empreendedores de si, através de uma lógica de caráter avaliativo do trabalho docente ${ }^{7}$ (FREITAS, 2018).

A atual diretriz formativa encaminha a formação inicial de professores numa lógica do tecnocratismo, que relega o profissional docente a utilizar práticas pedagógicas mecânicas de caráter puramente instrumental, separando o fazer e o pensar, priorizando a pedagogia neoliberal com ênfase nas competências explicitadas na BNCC. O pressuposto epistemológico é o de que a docência se faz pela reprodução de roteiros de conteúdo, elaborados por outros, externos à prática docente, na perspectiva meramente transmissiva e conteudista.

Segundo Freire (1997), essa separação entre o fazer e o pensar não é um fenômeno ingênuo, mas possui um viés ideológico, em que os docentes não apenas são excluídos do processo de concepção de educação, mas também permanecem à margem do debate público sobre a prática do ensino, da qual deveriam ser seus protagonistas mais imediatos.

De tal modo, vão se destituindo da formação inicial as bases pedagógicas que fundamentariam uma educação que venha a contribuir para a consolidação de uma nação soberana, democrática, justa, inclusiva, que promoveria a emancipação dos indivíduos e grupos sociais, contrária a toda forma de discriminação. De encontro a essa perspectiva emancipadora no processo inicial de formação, o atual documento infringe essa lógica e instaura todo o processo de formação com vistas a atender a BNCC, conforme explicita o seu 
o Art. 2: "É pressuposto da formação docente o desenvolvimento, pelo licenciando, das Competências Gerais da BNCC-Educação Básica" (BRASIL, 2019).

Indubitavelmente, o professor sofre um intenso processo de desprofissionalização, principalmente porque ele não se apropriará do seu trabalho, apenas garantirá os princípios de uma pedagogia de competências instituída na educação infantil e no ensino fundamental, propiciando a separação no âmbito da educação de quem pensa e quem executa. Segundo Contreras (2002, p. 224), “os docentes não só são excluídos do processo de concepção de educação, mas também permanecem à margem do debate público sobre a prática do ensino da qual são seus protagonistas mais imediatos".

Diante do atual cenário, não seria irresponsável a denúncia da implantação de uma concepção instrumental, mesmo que não superada por completo nos cursos de formação de professores, mas que vinha caminhando numa perspectiva de superação.

D’Ávila (2008) e Pimenta (2008) trazem à tona, em seus escritos, a problemática mencionada, fazendo uma incursão sobre os modelos de formação na contemporaneidade, pautados numa visão artesanal, instrumental-tecnicista, sociopolítica e nas perspectivas mais recentes ancoradas na epistemologia da prática e na fenomenologia existencial.

O primeiro modelo, que defende a formação docente numa perspectiva artesanal, de acordo com Pimenta (2008), está ancorado na observação e imitação de modelos do presente ou de um passado longínquo, atividade intuitiva, com caráter prático, e reforça a ideia da docência como ofício e não como profissão. Segundo D’Ávila (2008, p. 35), “esse modelo engendra uma formação baseada na idealização do ensino segundo as tradições, assim como representa a desqualificação profissional que presentemente se assoma ao quadro educacional em que estamos inseridos".

O segundo modelo, baseado na visão instrumental-tecnicista, ganha fôlego no período pós-1964, fruto da ditadura militar no Brasil. Essa realidade traz à tona o equívoco de formar professores pelo viés do modelo artesanal e técnico-instrumental, conforme D’Ávila (2008), segmentado em dois polos: um que caracteriza o trabalho na sala de aula e o outro que caracteriza as atividades de estágio. O primeiro traduz uma visão aplicacionista das teorias, pois enfatiza os conhecimentos acadêmicos, desprezando as práticas como fonte de conteúdos da formação. O segundo polo - visão ativista da prática - supervaloriza o fazer pedagógico, desprezando-se a dimensão dos conhecimentos disciplinares como instrumentos de análise 
contextual das práticas. Sustenta, assim, a dicotomia entre formação disciplinar e exercício das competências profissionais (com ênfase na instrumentação para o ensino), na separação entre ensino e pesquisa (a formação tem base quase exclusiva no conhecimento disciplinar e o papel da pesquisa não é enfatizado) e no reducionismo do conhecimento pedagógico a uma visão demasiadamente pragmatista (D’ÁVILA, 2008, p. 36).

Esses modelos explicitados anteriormente - artesanal e instrumental-tecnicista - têm sido, a partir do ano de 1980, alvo de críticas por não apresentarem subsídios formativos de aprendizagem da docência, em contrapartida, atualmente, assistimos a "um período estimulante em modelos de formação calcados sobre a construção da profissionalidade docente no, sobre e com o terreno profissional" (D’ÁVILA, 2008, p. 37).

Nóvoa (1992) já apontava a necessidade de novas abordagens a respeito da formação de professores, saindo de uma perspectiva centrada na dimensão acadêmica para uma perspectiva no terreno profissional, pessoal e de organização, a partir do contexto escolar. Ele alerta, inclusive, que a formação de professores tem ignorado o desenvolvimento pessoal, confundindo "formar e formar-se" (NÓVOA, 1992, p. 26).

Esse alerta nos direciona a pensar em uma proposta formativa que elege o sujeito como parte fundante no processo de formação, rompendo a visão externo-determinante que sustenta a formação de maneira externa, mediante as disciplinas curriculares e a ênfase no saber-fazer, conforme preconiza o atual documento oficial.

A formação de professores deve passar por dentro da profissão, isto é, deve basear-se na aquisição de uma cultura profissional (NÓVOA, 2009). Entender esta afirmação tão bem elaborada pelo autor parece ser o cerne da questão em torno da atual fragmentação e distanciamento entre a formação e o terreno de trabalho do professor. Essa consideração de Nóvoa é extremamente importante quando consideramos que os professores em formação provêm de diversos espaços e tempos culturais e considerar essa diversidade implica processos de formação cada vez mais complexos e diferenciados.

Em tempos tão complexos, a formação docente requer a presença de práticas críticas, voltadas à revisão dos pressupostos que fundam a docência como simplesmente aplicação técnica, superando os princípios de uma didática tecnicista, bancária, instrumental, e buscando a incorporação de pressupostos dialéticos, críticos, emancipatórios, na perspectiva 
de descolonizar a prática como reprodução de procedimentos e buscar superar a despersonalização do professor, tal qual preconizam os movimentos dos supostos reformadores da educação. O fazer-se docente requer também a aprendizagem criativa de técnicas de manejo do fenômeno educativo, que devem compor, de modo crítico, o rol de saberes que estruturam a docência como práxis social

\section{QUAL O SENTIDO DA DIDÁTICA MATERIALIZADA NA BNC DE FORMAÇÃO DE PROFESSORES?}

Sem o fundamento epistemológico da Pedagogia (como e para que ensinar?), a Didática torna-se um instrumento a favor da técnica acrítica, superficial, domesticadora. Uma concepção que pensávamos já ter sido superada a partir da década de 80, mas que escancara que o projeto de ensino está intrinsicamente ligado a uma prática educativa que é socialmente determinada por uma dinâmica social na luta de classes antagônicas. Nesse cenário, "os objetivos, conteúdos do ensino e o trabalho docente estão implicados às exigências sociais, políticas, econômicas e ideológicas" (LIBÂNEO, 2013, p. 18), portanto, a Didática também está implicada nessa dinâmica e, ao longo do contexto histórico, se reverberaram diferentes perspectivas no seu campo epistemológico.

Essas considerações apresentadas pelo professor Libâneo (1999) distam mais de duas décadas do atual cenário, e no atual cenário retratam de forma fidedigna as intencionalidades das reformas educacionais propostas pela BNCC, instituída no âmago da educação básica e na formação de professor, desvelando que a educação é também um espaço de disputa política e econômica dos grupos antagônicos de uma sociedade.

Desde o seminário "A didática em questão", realizado na PUC/Rio, em novembro de 1982, cujo objetivo era realizar uma revisão crítica do ensino e da pesquisa em didática, os pesquisadores da área reiteraram o consenso quanto ao objeto de estudo da didática no campo de formação de professor, qual seja: o de propiciar a análise crítica da realidade de ensino, abandonando a sua dimensão tecnicista. Contudo, alertamos para a urgente necessidade de a Didática realizar a leitura "oculta" do atual contexto para não retroceder e se embaraçar na armadilha da atual Resolução CNE 02/2019, que converge para a defesa de um ensino paralisado e bancário, podendo emaranhar o campo da Didática numa dimensão acrítica. 
Tem-se uma Didática sem Sujeitos, despersonalizada, a serviço, apenas, dos números e das estatísticas, despolitizada e sem compromisso com o social e o político da educação, necessidades tão bem expressas por Candau (1984), ao reivindicar uma Didática Fundamental, e também em Franco e Pimenta (2016), ao proporem a necessidade de uma Didática Multidimensional.

A BNC de formação inicial para professor obscurece a natureza de uma Didática muldimensional, invisibilizando-a no campo de formação de professor, mediante um processo de despersonificação que ancora o campo de estudo da didática ao discurso da lógica neoliberal, configurando as competências como a natureza primordial do processo de ensino.

A Didática Fundamental, caracterizada como mediadora entre as bases teóricas científicas da educação escolar e a prática docente (LIBÂNEO, 1999), tem o importante papel de (des)ocultar as armadilhas ideológicas e pedagógicas que estão na trama da educação e que, inevitavelmente, se reverberarão no ensino, desenhando uma concepção de homem e sociedade de senso utilitarista e afinados com a narrativa da meritocracia. Não obstante o cenário atual da educação brasileira seja um terreno pouco fértil, frente ao espaço ocupado pelas ideologias dominantes e traduzidas em documento curricular sob o prisma da BNCC para a educação básica em todo país, não é estéril para que a Didática produza investigações a partir de alguns questionamentos: 1) Quais pressupostos políticos e ideológicos se assentam na educação tendo como referência a BNCC? 2) Qual a finalidade social do ensino e da aprendizagem a partir da BNCC? 3) Pode a Didática se subordinar aos princípios políticos e pedagógicos do discurso das competências?

As discussões aqui propostas têm um amplo terreno de debate e não seria possível esgotá-las neste estudo, mas acenam para um debate profícuo de pesquisas no campo da Didática. A partir dos resultados, propiciariam caminhos para a formação de professor e para a educação, com vistas a superar a armadilha ideológica apresentada por uma pedagogia calcada nas competências e a-histórica. Isso ao se compreender que a educação e a escolarização, como práticas humanas, só podem ser entendidas no contexto das relações de trabalho constituídas socialmente e localizadas historicamente.

A Didática apresentada na BNCFP é destituída do seu campo epistemológico, tratada como ações práticas, esvaziadas, revestida de um caráter motivacional que condiciona o 
ensino e a aprendizagem como processos externos, relegada ao campo do behaviorismo pelo que conhecemos como "reforço" (SKINNER, 2007). Portanto, destituída do seu caráter intercultural, político, multidimensional e eclipsada pelas metodologias específicas; no documento, ganha relevo uma perspectiva comportamentalista no campo da Didática.

Mascarenhas (2018) já denunciava a dúvida e o descrédito em relação ao importante papel da Didática nos currículos dos cursos de Licenciatura. Uma depreciação que resultava na ínfima carga horária dessa disciplina nos currículos e a recorrente dúvida de docentes universitários sobre a real necessidade da Didática no currículo, ao defenderem que as disciplinas específicas já cumpriam o papel da Didática da área de formação. Em vista disso, muitos professores universitários ecoavam para uma compreensão de eliminação da disciplina de Didática, justificando tal premissa a partir da defesa das metodologias de ensino ou metodologias específicas como disciplinas que substituem a Didática. Essa ideia é imprópria e "descabida", evidenciando a total falta de clareza da singularidade que cumpre a Didática nos currículos de formação de professores e a necessidade de integração e não eliminação desta área de conhecimento em detrimento das didáticas específicas (LIBÂNEO, 2008).

Há que se entender que a Didática e as metodologias específicas cumprem a ponte entre a teoria pedagógica e a prática educativa escolar, ajudando os professores a internalizarem modos de ação assentados numa teoria prática e numa prática teórica. Assim, no processo de construção dos conhecimentos profissionais dos futuros professores, é inegável a importância da "Didática fundamentada sem destituir o terreno das didáticas específicas, com suas singularidades etimológicas e pedagógico didáticas" (D’ÁVILA, 2012, p.39).

Assim, a didática na formação de professores tem o papel de propiciar a análise crítica da realidade do ensino, buscando compreender e transformar essa realidade de forma articulada a um projeto político de educação transformadora. E neste aspecto, a atual Diretriz de formação de professores é uma política inócua na construção de professores críticos e engajados na transformação de sujeitos emancipatórios e conscientes de uma profissionalidade calcada na práxis.

\section{CONSIDERAÇÕES PARCIAIS}


A denúncia explicitada neste estudo não consegue dar conta de evidenciar todas as mazelas e retrocessos no campo da formação de professores e, como consequência, as implicações nas relações de um ensino que vai, cada vez mais, se instituindo como uma prática de caráter aplicacionista, imposta como padrão formativo a professores, que aos poucos vão subjetivando a didática como procedimento meramente instrumental de atividades e supostas competências. Por que ignorar os estudos e pesquisas de tantos grupos que investigam a questão da formação? Por que destituir uma política de formação de professor (Resolução 02/2015) que ainda não havia sido avaliada? Essas questões não foram respondidas, pois não foram fruto deste trabalho, mas explicitam que existe um rico campo para debate e insurgências em relação a essa política autoritária e degradativa de formação docente numa perspectiva crítica.

Quais subsídios sustentam nossa análise em torno das considerações (parciais) da pergunta investigativa do estudo: desvelar os pressupostos pedagógicos, formativos, políticos e ideológicos presentes na Resolução CNE 02/2019 que orientam as diretrizes de formação de professores. Com base nessa inquietação, aportamos a nossa análise nos seguintes logrados:

a) Os princípios formativos presentes na Resolução 02/2019 não se inserem num contexto social e histórico, mas ancoram a formação docente a princípios meramente técnicos e aplicacionistas, conduzindo o processo formativo no âmbito das instituições de ensino superior para currículos esvaziados, centrados numa lógica de competências, desconsiderando o professor como um profissional crítico, destituindo a sua formação de um caráter político, social estético e intercultural;

b) O sentido de prática ancorada na atual diretriz evidencia um praticismo, uma prática imobilizada num "receituário" de habilidades e competências no qual o docente deve introjetar no aluno, uma prática a-histórica, dimensionada por um ensino bancário e sem significado social;

c) E a Didática? Declaradamente, uma didática instrumental por aproximações de "manejo de ritmos", numa lógica de ensino e aprendizagem com uma concepção exógena, despolitizada, galgada no terreno de uma psicologia behavorista, que concebe o sujeito a partir da punição e do reforço. É visível a desautorização do campo epistemológico da Didática! 
d) Mais uma vez, reafirmamos a má intenção posta no referido documento, que chega de forma autoritária e desrespeitosa aos educadores e pesquisadores da temática. Mais uma vez, uma política para calar e retirar o protagonismo docente de sua própria atividade e espaço profissional.

Reafirmamos que os professores não podem ser considerados apenas reprodutores de mudanças propostas por técnicos que, muitas vezes, desconhecem as necessidades pedagógicas de alunos; será preciso resgatar o propósito intelectual/moral que deve subsidiar a tarefa pedagógica.

Concluímos que o referido documento explicita um profundo reducionismo na consideração do papel do professor; um inaceitável reducionismo na desconsideração das desigualdades sociais, tanto de alunos como de professores; e um reducionismo expresso pelo desrespeito à autonomia e autoridade social do professor, invisibilizando sua capacidade/necessidade de decidir nos enfrentamentos da complexa tarefa de educar. A formação por competências desconsidera a necessidade de enfrentar com responsabilidade os desafios atuais da educação que precisa atuar num mundo plural e de imensa diversidade cultural, social, econômica e pessoal. Uma educação que precisa envolver-se com processos de ampla inclusão e de justiça cognitiva.

\section{REFERÊNCIAS}

APPLE, Michael. Ideologia e currículo. São Paulo: Brasiliense, 1982.

BALL, Stephen; OLMEDO, Antonio. A 'nova' filantropia, o capitalismo social e as redes de políticas globais em educação. In: PERONI, Vera Maria Vidal (Org.). Redefinições das fronteiras entre o público e o privado: implicações para a democratização da educação. Brasília: Liber Livro, 2013. p. 33-47

BRASIL. Conselho Nacional de Educação. Resolução CNE/CP n ${ }^{\circ}$ 02/2015, de $1^{\circ}$ de julho de 2015. Define as Diretrizes Curriculares Nacionais para a formação inicial em nível superior (cursos de licenciatura, cursos de formação pedagógica para graduados e cursos de segunda licenciatura) e para a formação continuada. Diário Oficial [da] República Federativa do Brasil, seção 1, n. 124, p. 8-12, Brasília, 02 de julho de 2015.

BRASIL. Ministério da Educação. Conselho Nacional de Educação. Resolução no 2, de 20 de dezembro de 2019. Define as Diretrizes Curriculares Nacionais para a Formação Inicial de Professores para a Educação Básica e institui a Base Nacional Comum para a Formação 
Inicial de Professores da Educação Básica (BNC-Formação). Diário Oficial da União (DOU $n^{\circ} 247,23.12 .2019$, Seção 1, p.115).

CANDAU, Vera Maria (Org.). A Didática em Questão. 17. ed. Petrópolis: Vozes, 1984.

CONTRERAS, José. A autonomia de professores. São Paulo: Cortez, 2002.

DARDOT, Pierre; LAVAL, Christian. A nova razão do mundo: ensaio sobre a sociedade neoliberal. São Paulo: Boitempo, 2016.

D’ÁVILA, Cristina Maria. A didática nas Diretrizes Curriculares Nacionais e Base Nacional Comum para a Formação de Professores da Educação Básica: impasses, desafios e resistências.Revista Cocar, Edição Especial, n.8, p. 86-1011, jan./abr. 2020. Disponível em: https://periodicos.uepa.br/index.php/cocar/issue/view/172. Acesso em: 18 mar. 2020.

D’ÁVILA, Cristina Maria. Formação docente na contemporaneidade: limites e desafio.

Revista da FAEEBA: Educação e Contemporaneidade, Salvador, v. 17, n. 30, p. 33-41, jul./dez. 2008. Disponível em: https://www.revistas.uneb.br/index.php/faeeba/. Acesso em: 15 set. 2018.

D’ÁVILA, Cristina Maria. Didática: a arte de formar professores no contexto universitário. In: D'ÁVILA, Cristina Maria; VEIGA, Ilma Passos Alencar (Orgs.). Didática e docência na educação superior: implicações para a formação de professores. Campinas: Papirus, 2012. p. 7-14.

FRANCO, Maria Amélia Santoro. O lugar do professor na pesquisa educacional. Santos: Editora Universitária Leopoldianum, 2005.

FRANCO, Maria Amélia Santoro e PIMENTA, Selma. Didática multidimensional: por uma sistematização conceitual. Educ. Soc. [online]. 2016, vol.37, n.135, pp.539-553. Disponível em: https://www.cedes.unicamp.br/. Acesso em: 12 abr. 2020.

FREIRE, Paulo. Professora sim, tia não: cartas a quem ousa ensinar. São Paulo: Olho D’Água, 1997.

FREITAS, Luiz Carlos de. Os reformadores empresariais da educação: da desmoralização do magistério à destruição do sistema público de educação. Educação e Sociedade, Campinas, v. 33, n. 119, p. 379-404, 2012. Disponível em: https://www.cedes.unicamp.br/. Acesso em: 20 maio 2019.

FREITAS, Luiz Carlos de. A reforma empresarial da educação: nova direita, velhas ideias. São Paulo: Expressão Popular, 2018. 
FRIGOTTO, Gaudêncio. Educação e formação humana: ajuste neoconservador e alternativa democrática. In: GENTILI, Pabulo Antonio Amadeu; SILVA, Tomaz Tadeu (Orgs.).

Neoliberalismo, Qualidade Total e Educação - Visões Críticas. Petrópolis, RJ: Vozes, 1994. p. 31-92.

GENTILI, Antonio Pablo. O discurso da "qualidade" como nova retórica conservadora no campo educacional. In: GENTILI, Pabulo Antonio Amadeu; SILVA, Tomas Tadeu (Orgs.). Neoliberalismo, Qualidade Total e Educação - Visões Críticas. Petrópolis, RJ: Vozes, 1994. p. 11-178.

HARGREAVES, Andy. Hacia uma geografia social de la formación docente. In: RASCO, Jose Felix Angulo; RUIZ, J. Barquín; GÓMEZ, Angel Ignácio Pérez. Desarrolo profesional del docente: Política, investigación y práctica. Madrid: Akal Editora, 1999. p. 31-91.

KINCHELOE, Joe L. A formação do professor como compromisso político. Mapeando o pós-moderno. Porto Alegre: Artes Médicas, 1997

LIBÂNEO, José Carlos. Pedagogia e pedagogos, para quê? 2.ed. São Paulo: Cortez, 1999.

LIBÂNEO, José Carlos. Didática e epistemologia: para além do embate entre a didática e as Didáticas específicas. In: VEIGA, Ilma P. A.; D’ÁVILA, Cristina (Orgs.). Profissão docente: novos sentidos, novas perspectivas. Campinas: Papirus, 2008. p. 57-69.

LIBÂNEO, José Carlos. Didática. São Paulo: Cortez, 2013.

MASCARENHAS, Aline D. Nunes. Didática e didáticas específicas: imprecisões no campo da formação de professores. In: ENCONTRO NACIONAL DE DIDÁTICA E PRÁTICA DE ENSINO, 19., 2018. Salvador. Anais... Salvador, UFBA, 2018.

NÓVOA, António. Professores Formação de professores e profissão docente. In: NÓVOA, António (Org.). Os professores e a sua formação. Lisboa: Publicações Dom Quixote, 1992. p. 13-33.

NÓVOA, António. Imagens do futuro Presente. Lisboa: Educa, 2009.

OLIVEIRA, Dalila Andrade. Políticas itinerantes de educação e a reestruturação da profissão docente: o papel das cúpulas da OCDE e sua recepção no contexto brasileiro. Revista Currículo sem Fronteiras, v. 20, n. 1, p. 85-107, jan./abr. 2020. Disponível em: www.curriculosemfronteiras.org. Acesso em: 20 fev. 2020.

PERRENOUD, Philippe. Construir as competências desde a escola. Porto Alegre: Artmed, 1999.

PIMENTA, Selma. Professor reflexivo: construindo uma crítica. In: PIMENTA, Selma Garrido.; GHEDIN, Evandro (Orgs.). Professor reflexivo no Brasil: gênese e crítica de um conceito. 5. ed. São Paulo: Cortez, 2008. p. 17-52 
POPKEWITZ, Thomas. Uma perspectiva comparativa das parcerias, do contrato social e dos sistemas racionais emergentes. In: TARDIF, Maurice.; LESSARD, Claude (Orgs.). O ofício de professor: história, perspectivas e desafios internacionais. Petrópolis: Vozes, 2008. p. 234254.

SHIROMA, Eneida Oto; EVANGELISTA, Olinda. A colonização da utopia nos discursos sobre profissionalização docente. PERSPECTIVA, Florianópolis, v. 22, n. 2, p. 525-545, jul./dez. 2004. Disponível em: http://www.ced.ufsc.br/nucleos/nup/perspectivas.html. Acesso em: 20 ago. 2018.

SKINNER, Bruner. F. Ciência e comportamento humano. São Paulo, SP: Martins Fontes, 2007.

TORRES, Rosa Maria. Tendências da formação docente nos anos 90. In: WARDE, Miriam Jorge (Org.). Novas políticas educacionais: críticas e perspectivas. São Paulo: PUC-SP, 1998.

VÁSQUEZ, Adolfo. S. Filosofia da práxis. 2. ed. Rio de Janeiro: Paz e Terra, 1977.

\section{NOTAS:}

1. O TPE foi criado, em 2006 com uma agenda em defesa da educação pública, mas na realidade sintetiza a agenda do capital para a educação: a formação de competências e habilidades dos trabalhadores para servirem aos interesses do mercado, definição de metas de desempenho da educação básica por marcos avaliatórios.

2. Nova filantropia se caracteriza pela relação direta com a 'caridade' e os 'resultados' e o envolvimento direto dos doadores nessas ações filantrópicas e nas comunidades políticas. (BALL; OLMEDO, 2013).

3. Observatório da prática docente. FRANCO, Maria Amélia Santoro 2010-2019. Pesquisa CNPq.

4. Grupo de pesquisa: Interlocuções entre educação em direitos humanos, currículo e formação de professores. CNPq.

5. Grupo de Pesquisa: Pedagogia Crítica: pesquisa e Formação. CNPq/CAPES.

6. Termo atribuído por Fabre (1992) ao se referir a uma prática docente que não consegue estabelecer mediações entre a teoria e a prática.

7. A política itinerante de formação de professor é um movimento em âmbito mundial, como processo de globalização, sustentada pela noção de qualidade na educação não mais como um conceito subjetivo, mas definida por um número ou indicador do que se espera na educação.

8. A atual BNC de formação inicial de professor sinaliza para o processo avaliativo não só de professores em exercício na educação básica, mas também exames pós-formação inicial. Freitas (2018) nos adverte que já tramita no Congresso Nacional um projeto de lei para instituir o Exame Nacional de Avaliação do Magistério da Educação Básica (Enameb).

Recebido em: 22/01/2021

Aprovado em: 07/05/2021 